\title{
ARTICLE
}

\section{Evaluating the gamma dose rate for the liquid waste treatment facility in Fukushima site with Attila radiation transport code}

\author{
Eric Castanier* and David Kerouanton
}

AREVA-E\&P: 1 rue des Hérons, 78182 Saint Quentin en Yvelines, France

\begin{abstract}
A decontamination system was co-developed by AREVA ${ }^{\mathrm{a}}$ and Veolia Water ${ }^{\mathrm{b}}$ for the Fukushima Daiichi nuclear plant. This system is designed to reduce the water radioactivity level by a factor of 10000 and to treat up to 50 tons of contaminated waters per hour. The ambient gamma dose rate (DER) is calculated in the Radioactive Waste Treatment Facility by using the 3D-Sn ATTILA ${ }^{\circledR} 7.1$ code in the aim of planning maintenance. Especially, DER iso-curves allow defining quickly the ways which minimize radiological exposure of the maintenance teams.
\end{abstract}

Keywords: Fukushima; 3D-Sn; gamma dose rate

\section{Context}

Installed on the Fukushima site that was severely damaged following an earthquake and tsunami that hit the North-East of Japan in March 2011, the decontamination system was designed, constructed, and launched in a record-short time (2 months) and was an essential element to stabilize the situation of the nuclear plants. It will improve the access of workers to strategic parts of the site, and allow TEPCO (Tokyo Electric Power Company) to re-circulate the waters that are used for cooling the reactors. Constructed and commissioned by AREVA and Veolia experts, the system reduces the water radioactivity level by a factor of 10000 and can treat up to 50 tons of contaminated waters per hour [1]. This system uses a combination of technologies which have proven track record in AREVA's La Hague and Marcoule facilities and across hundreds of Veolia Water projects in the world.

\section{Decontamination process}

The general process operating principle is composed of two physico-chemical adsorption-clarification stages set in series in order to meet expected Cs activity reduction factor (DF).

The filled treatment line (see Figure 1) is composed of the following unit operations:

- Pre-treatment 1: bar screen to remove large materials,

\footnotetext{
* Corresponding author. Email: eric.castanier@areva.com
}

- $\quad$ Pre-treatment 2: Dissolved Air Flotation (DAF) unit for Oil removal,

- $\quad$ Adsorption stage 1: contact tank with adsorbents injection + clarification with MULTIFLO ${ }^{\text {TM }}{ }^{\mathrm{c}}$ unit,

- $\quad$ Adsorption stage 2: contact tank with adsorbents injection + clarification with ACTIFLO ${ }^{\mathrm{TM}}{ }^{\mathrm{C}}$ unit,

- Final filtration: polishing disk filter unit to remove adsorbent potentially entrained in the treated water (prevention of outflow of suspended solids).

The pre-treated water from DAF unit is pumped to a pre-contact tank where adsorbents are injected. These effluents feed the MULTIFLO ${ }^{\mathrm{TM}}$ unit where ferric coagulant in the coagulation tank and polymer in the maturation tank are injected. Sludge is concentrated in

a AREVA supplies solutions for power generation with less carbon. Ranked first in the global nuclear power industry, AREVA's unique integrated offering to utilities covers every stage of the fuel cycle, nuclear reactor design and construction, and related services. The group is also expanding in renewable energies to be one of the top three in this sector worldwide in 2012. AREVA's 48,000 employees are helping to supply ever safer and cleaner to the greatest number of people. b Veolia Water is a part of the Veolia Environment Group, a
worldwide reference in environmental solutions. With nearly
3000 employees in Japan, Veolia Water is present in the country
mainly in the management of water and wastewater projects,
maintenance services and supply of water solutions and
technologies.

\footnotetext{
${ }^{\mathrm{c}}$ MULTIFLO $^{\mathrm{TM}}$ and ACTIFLO ${ }^{\mathrm{TM}}$ are Veolia Trademarks.
} 


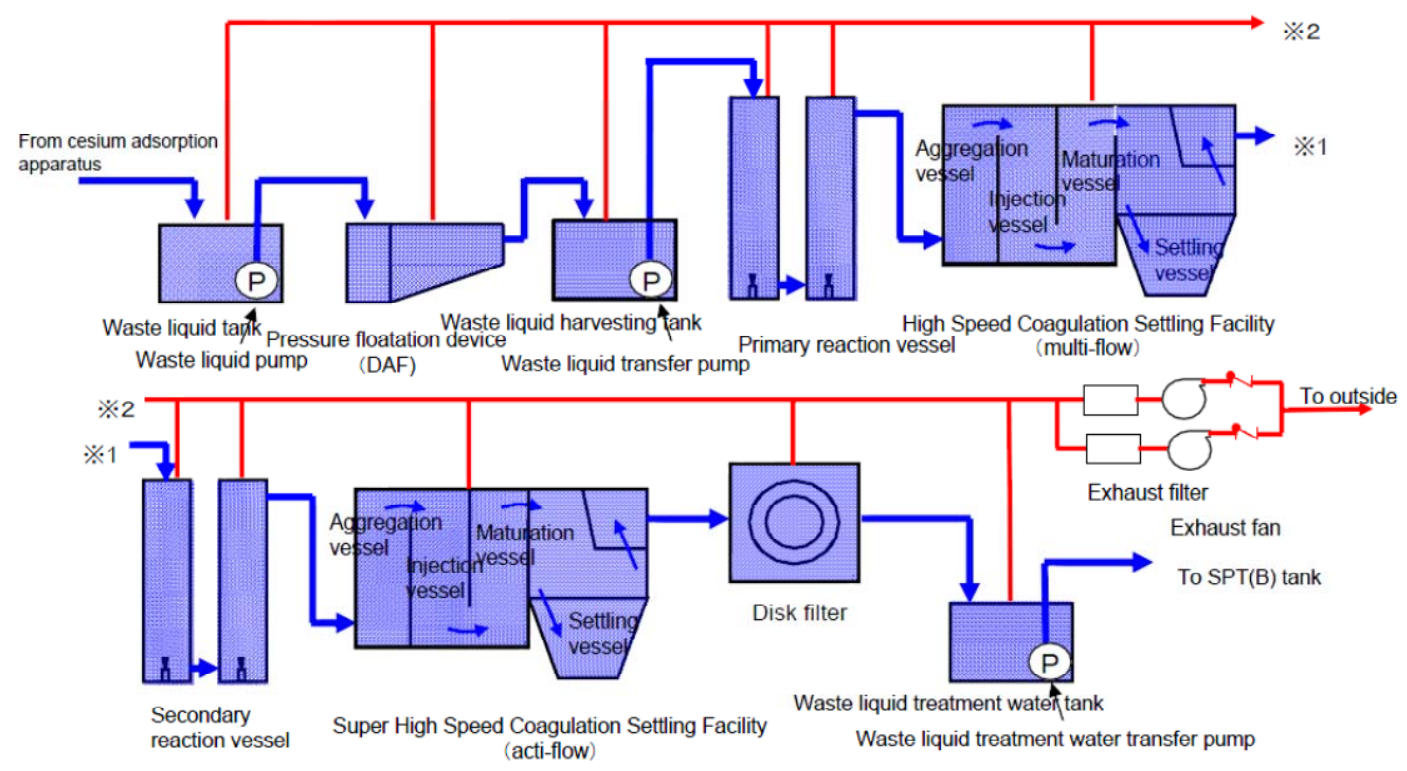

Figure 1. Decontamination water treatment process (source : TEPCO - with courtesy of Veolia Water).

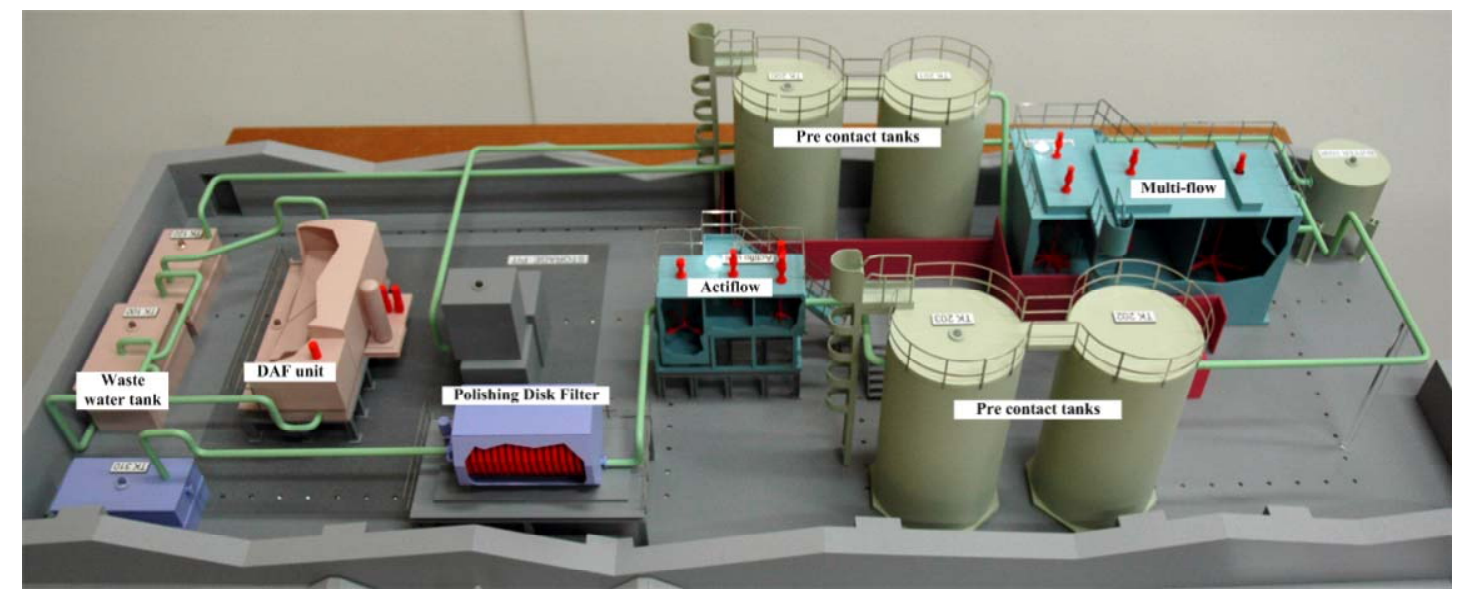

Figure 2. Decontamination equipments layout.

the settler, a part is recycled in the pre-contact tank, and the remaining part forms a concentrated sludge which had to be stored.

The effluent feeds the pre-contact tank of the ACTIFLO $^{\mathrm{TM}}$ unit. The supernatant flow from MULTIFLO $^{\mathrm{TM}}$ unit is introduced to a pre-contact tank where adsorbents are injected. Then the effluent feeds the ACTIFLO ${ }^{\mathrm{TM}}$ unit where ferric coagulant in the coagulation tank and polymer in the maturation tank are injected. Sludge is concentrated in the settler. Finally, treated water from ACTIFLO ${ }^{\mathrm{TM}}$ unit is injected in the disk filter unit to avoid any significant release of adsorbent.

\section{Model}

\subsection{Codes}

The gamma spectra are established by ORIGEN2.2 code [2].

Ambient gamma dose rate (DER) iso-curves are assessed by ATTILA 7.1 code [3]. ATTILA 7.1 is a three dimensional (3-D) $S_{n}$ transport theory code. Attila solves the linearized Boltzmann transport equation in first order form using a tri-linear discontinuous spatial differencing on an arbitrary tetrahedral mesh. Attila comes with a graphical user interface (GUI) which allows direct integration with CAD software programs such as Solidworks $^{\circledR}$. A post processor is available for visualization of the 3-D results.

DER are converted from fluxes with ICRP74 coefficients [4].

\subsection{Geometry}

The decontamination equipments layout is shown Figure 2.

No operators are allowed to come into the process cell during normal operation (when the treatment line is 
operating and therefore filled). It must be emptied and rinsed out before. In this case, residual volumes remain in equipments leading to residual dose rates.

\subsection{Source data}

The isotopic composition of the effluents is issued from measured values at the entrance of the decontamination facility.

\subsection{Attila model}

The cells number is about 1,200,000 (see Figure 3). Calculations are performed with a triangular Chebychev Legendre quadrature and a Sn order of 32.

A gamma cross section library based on RADION15 XS library [2] with a specific group structure (34 groups, $11 \mathrm{MeV}-1 \mathrm{E}-3 \mathrm{MeV}$ ) is used.

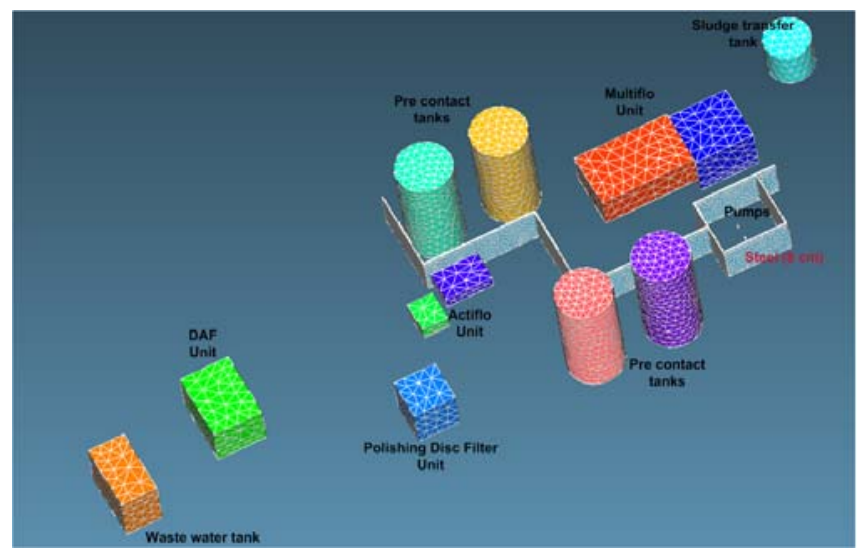

Figure 3. Example of source meshing when equipments are filled.

Taking into account of activity levels and in order to simplify calculations, both MULTIFLO ${ }^{\mathrm{TM}}$ and ACTIFLO ${ }^{\mathrm{TM}}$ units have been divided in two parts.

The sludge transfer tank is not active (empty) at the moment and no pipes contributions are considered for DER calculations.

\section{Results}

\subsection{Validation}

The results when the decontamination system was operating (all equipments filled) are compared to measured values. We find a very good agreement between ATTILA calculation results and the measured values (see 2D iso-DER surfaces on Figure 4).

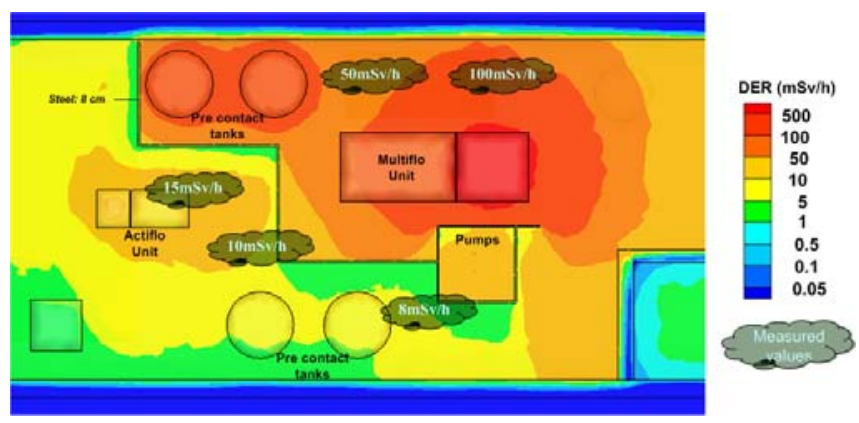

Figure 4. 2D iso-DER surfaces (height $=1 \mathrm{~m}$ ) in the hot cell when all equipments are filled.

\subsection{DER iso-curves}

To help the maintenance teams to plan operations, we use the DER iso-curves $(\mathrm{mSv} / \mathrm{h})$ in the active cell when all equipments are emptied and rinsed as shown on the Figure 5.

Calculations show that DER is lower than $0.5 \mathrm{mSv} / \mathrm{h}$ in most parts of the cell and that the absorbed dose for maintenance operations of the DAF unit or the ACTIFLO $^{\mathrm{TM}}$ unit can easily be optimized.

Note: since no pipes contributions have been considered for DER calculations, it should be anticipated that the absorbed doses will be slightly higher in reality.

In addition, ATTILA allows the plot of 3D iso-DER surfaces as shown on Figure 6. This appears also helpful to optimize radiological exposure. For example, Figure 6 shows that DER greater than $5 \mathrm{mSv} / \mathrm{h}$ are limited to shielded area, while DER do not exceed $1 \mathrm{mSv} / \mathrm{h}$ in the major part of the cell below $2 \mathrm{~m}$ level.

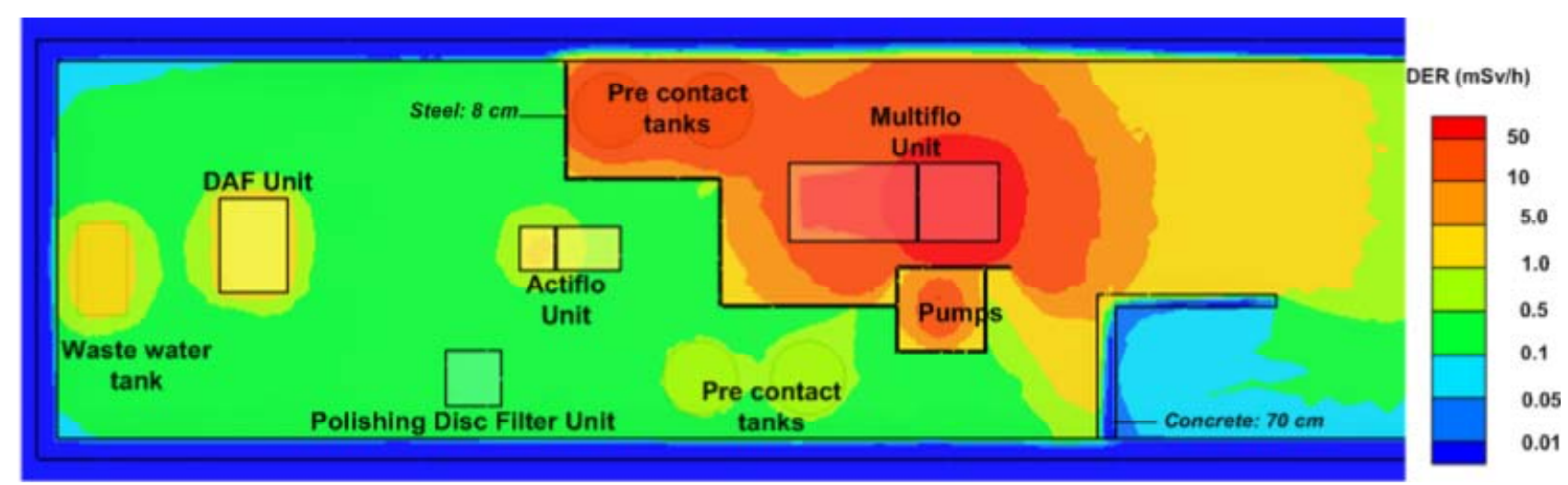

Figure 5. DER iso-curves (height $=1 \mathrm{~m}$ ) in the hot cell when emptied and rinsed out. 

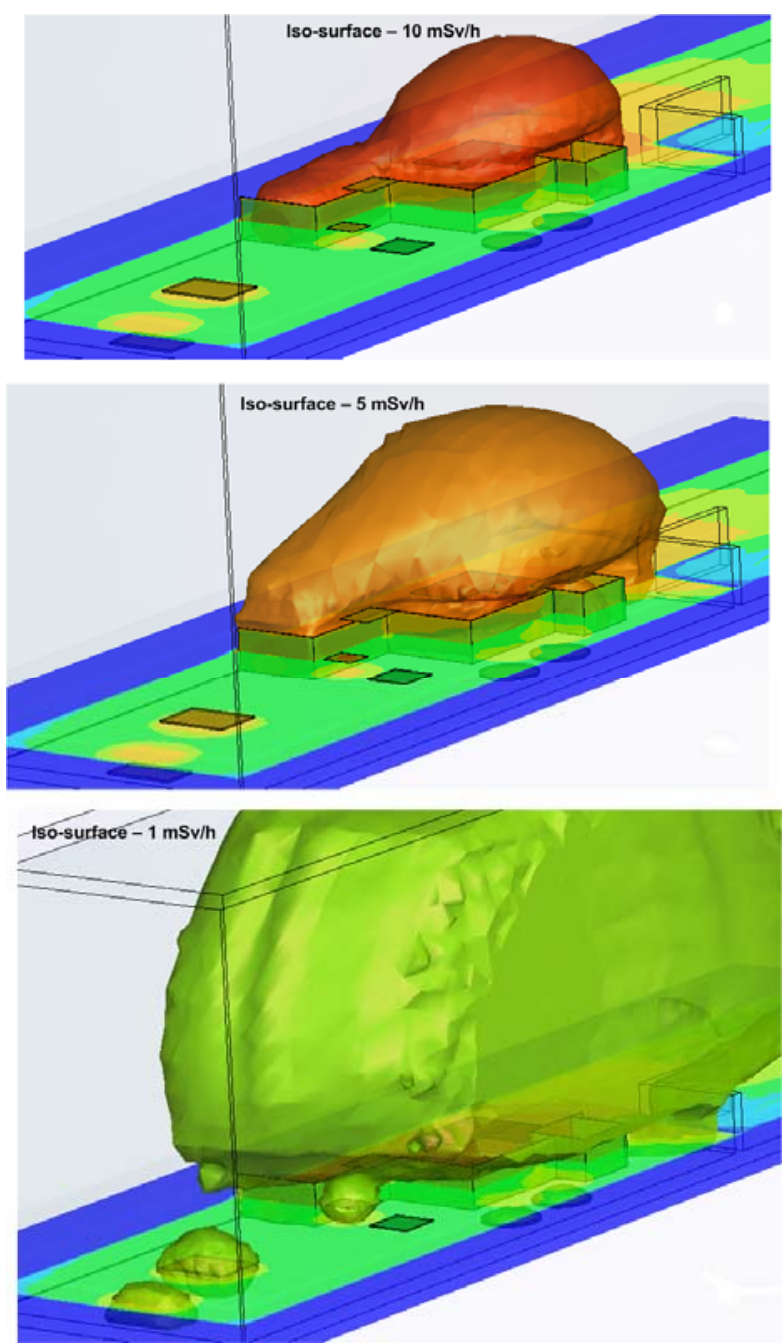

Figure 6. DER iso-surfaces in the hot cell.

\section{Conclusion}

The ambient gamma dose rate in the Radioactive Waste Treatment Facility in Fukushima site was calculated by using the 3D-Sn ATTILA ${ }^{\oplus} 7.1$ code in view of planning maintenance.

Especially, iso-DER surfaces allow defining quickly the ways which minimize radiological exposure of the maintenance teams. Thanks to this method, dose rate are optimized during maintenance

\section{Acknowledgements}

Special thanks to Mr Gregory Failla and Mr Ian M. Davis for their helpful assistance on Attila functions.

\section{References}

[1] A. Gay, P. Gillet, B. Ytournel, T. Varet, L. David, T. Prevost, C. Redonnet, G. Piot, S. Jouaville and G. Pagis, Multi-phased, post-accident support of the Fukushima Dai-Ichi Nuclear Power Plant, WM 2012, Phoenix AZ, Feb 27-Mar 1, 2012.

[2] A.G. Croff, A Users Manual for ORIGEN2 Computer Code, ORNL/TM-7175, Oak Ridge National Laboratory, (1980).

[3] J.M. McGhee, T.A. Wareing and D.A. Barnett Jr, Attila User's Manual, Transpire Inc., (2007).

[4] ICRP publication 74, Conversion Coefficients for use in Radiological Protection against External Radiation, Annals of the ICRP 26(3/4) (1996). 